\title{
AN APPLICATION OF STOCHASTIC FRONTIER GRAVITY APPROACH (THE CASE OF IRAN'S POTENTIAL AGRICULTURAL EXPORTS)
}

\section{SHOKROLLAH HAJIVAND, REZA MOGHADDASI*, YAAGHOOB ZERAATKISH, AMIR MOHAMMADINEJAD}

Department of Agricultural Economics, Education and Extension, Science and Research Branch, Islamic Azad University, Tehran, Iran

*Corresponding author: r.moghaddasi@srbiau.ac.ir

ABSTRACT. Agriculture plays a crucial role in Iranian economy in terms of food supply, job creation, food security, and foreign earnings. The main purpose of this study is to provide an estimate of the country's agricultural exports potential and to determine how efficient Iran is in realizing this capacity. Using data for 38 destination countries for the period spanning from 1982 to 2017, proper stochastic frontier gravity model was estimated. Main findings revealed direct and significant impact of trade partners' GDP and population on Iran's agricultural exports, while distance and border barriers imposed by destination countries show significant reverse effect. Furthermore, on average, 69 percent of the country's agricultural export potential has been realized through the study period. Measures to promote competitive exports along with pursuing free bilateral and regional trade agreements for removing border barriers are recommended.

\section{INTRODUCTION}

Export potential is the maximum amount of exports which is realized in free (no impediment or restriction) trade between nations. Such an amount can be determined for any level of export drivers (Miankhel et al. in [1]). Due to heterogeneity of countries in terms of economic development, trade relationships and border policies, different factors might be responsible for inefficiency in realizing trade potential. Some exist within the exporting country (internal factors) while others relate to destination countries (external factors).

Received January 18 th 2020 ; accepted February 21st, 2020; published May 1st, 2020.

2010 Mathematics Subject Classification. 62P20, 91G70.

Key words and phrases. potential exports; stochastic frontier gravity model; agriculture; Iran.

(02020 Authors retain the copyrights 
Moreover, due to more severe rigidities, it seems viable assuming that 'external factors' exert stronger prohibitive impact on export potential in developing countries than developed nations.

From the policy-making point of view knowing trade potential for different products with corresponding trading partners is of great importance as it provides insights on public trade policies' efficiencies as well as a guide for necessary reforms and trade negotiations to get export potential fully exploited. For almost six decades, the gravity model has been the most common tool among economists interested in analysis of trade flows between countries. (Baier and Bergstrand in [2]; Anderson and Wincoop in [3]).

The first application of this model in economics dates back to 1960's inspiring from the Newton's physical gravity model which has been introduced in 1687 (Linder in [4]; Tinbergen in [5]). Lack of theoretical background on one hand and their purely empirical nature on the other hand, have put early papers under serious criticism. Anderson in [6] made the first attempt to prove that theoretical justification for the gravity model exists. Further the same assumption was used by Bergstrand in [7], who aimed at developing further the microeconomic foundations of the gravity equation. Helpman and Krugman in [8] used the same assumptions and the same constant elasticity of substitution (CES) utility function to again prove that the gravity equation is consistent with theory of international trade. Deardoff in [9] derived the gravity equation from the well-known two-factor, twocommodity Heckscher-Ohlin model. All of that allowed economists to see that the gravity approach to estimating trade flows is not only a useful technique, but can also be transformed in many ways to analyze other issues of international trade.

Agriculture is recognized as a key sector in Iranian economy. It constitutes about 9.5 percent of gross domestic product, while its share in total workforce, non-oil exports and food supply is reported at 23, 21, and 80 percent, respectively (CBI ${ }^{1}$ in [10]). As a source of non-oil foreign earning, there is high priority on agricultural exports promotion in national five-year development plans. Iran has exported, on average, USD 1.3 billion agricultural products (raw and processed) to the world each year during 1982-2017 rising from USD 250 million in 1982 to more than USD 2.7 billion in 2017. Despite of this remarkable growth, a common belief is that the country's capacity to touch higher figures is great (Roosta et al. in

${ }^{1}$ Central Bank of Iran 
[11]). So, this paper tries to empirically quantify Iran's agricultural export potential for different trading partners.

\section{MATERIALS AND METHODS}

The difference between real (observed) exports and the predicted (fitted) values is commonly defined as potential exports. Estimation of the gravity equation with ordinary least squares (OLS) to find trade potential between a pair of countries leads to estimates that represent the centered values of the data set. However, potential trade refers to open and frictionless trade between countries. Thus, for policy purposes, it is sensible to define potential trade as the maximum trade that can occur between any two countries which have bilaterally liberalized trade regimes given the conventional determinants of trade (size of the trading countries, the geographical distance, etc.).

This means that the estimation of potential trade requires a procedure that represents the upper limits of the data instead of its centered values (Kalirajan in [12]). In addition, in the conventional gravity model, it is also arguable that trade costs are dependent not only on geographical distance between countries but also on other factors emanating from the existing infrastructural, institutional, socio-economic, and political rigidities in both trade partners. These latter costs are defined as 'economic distance' in the literature (Anderson in [6]). Thus, the conventional gravity model given above has omitted this potentially important explanatory variable. Furthermore, this inherent omitted variable bias is overlooked by OLS estimation.

In simpler language, omission of the economic distance term leads to heteroskedastic errors which results in bias in the estimation of the model parameters. The log-linearization of the empirical model in the presence of heteroskedasticity leads to inconsistent estimates because the expected value of the logarithm of a random variable depends on higher-order moments of its distribution (Silva and Tenreyro in [13]). Also, it affects the normality assumption of the error term (Matyas in [14]). As a result, an ordinary least squares estimation will lead to biased results (Kalirajan in [12]).

Following Kalirajan in [12] and Miankhel et al. in [1], the gravity equation for exports can be estimated alternatively as:

$\operatorname{Ln} X_{i j}=\operatorname{Ln} f\left(Z_{j}, \beta\right) \exp ^{\left(v_{i}-u_{i}\right)}$

where the term $X_{i j}$ represents the actual exports from country i (Iran in this study) to country j. The term $f\left(Z_{j}, \beta\right)$ denotes a function of the drivers of potential bilateral trade $Z_{j}$, 
which include distance, GDP, and population to represent supply and demand conditions, and $\beta$ is a vector of unknown parameters. The inclusion of the composite error term in the above gravity equation, which accounts for the impact of other unobservable variables influencing exports costs, is to remove the bias that is inherent in the conventional gravity model.

To estimate equation (1), the stochastic frontier framework is used. The SFGM 11 recognizes two separate groups of constraints on export including behind and beyond border constraints. The latter can be divided into explicit beyond the border constraints, which are observable, and implicit beyond the border constraints, which are not observable. Explicit beyond the border constraints, for example, can be measured from the applied tariffs of importing countries (Kalirajan and Singh in [15]; Miankhel et al. in [1]). Implicit beyond the border constraints, which emanate from institutional weaknesses and policy rigidities existing in the importing countries, are difficult to measure and are commonly considered as given. However, Miankhel et al. in [1] address this issue and highlight that implicit beyond the border constraints affect the exporting countries uniformly. Through the trade balance relationship equation in Anderson's theoretical framework for the gravity model, the implicit beyond the border constraints would affect, and may probably reduce, planned expenditures in exporting countries if the exporting countries are not taking measures to overcome these constraints through conforming to, or initiating, certain measures for becoming more efficient (Anderson in [6]).

In order to overcome implicit beyond the border constraints, and to maintain their market shares or realize their export potential, exporting countries need to become more efficient by removing behind the border constraints. These put additional transaction costs on the trade flows. These costs include institutional costs stemming from the inefficient prevalent practices in the institutions, regulatory and legislative costs, equipment and training costs, and political costs due to the inability to take on trade facilitation measures due to geostrategic interests. Specific behind the border measures could range from product standards and conformity assessment measures, business facilitation, and trade financing, to hard (physical) and soft (regulatory) infrastructure including efficient transport links and logistics and poor governance in the regulatory institutions. Behind the border constraints could also be due to the retention of imperfect institutions, caused by rent seeking agents

1 Stochastic Frontier Gravity Model 
through lobbying, and resistance from the elite towards introducing institutional innovations. In addition, these costs could come from the stance of certain institutions aimed at achieving policy objectives.

Following the methodology given above, behind the border constraints and explicit beyond the border constraints are included within the gravity equation in the form of $\mu_{\mathrm{i}}$ and trade weighted effective applied tariffs, respectively.

$$
\operatorname{Ln} X_{i j}=\operatorname{Ln} f\left(Z_{j}, \beta\right) \exp ^{\left(\text {tariff } v_{i}-u_{i}\right)} \text {, }
$$

The single sided error term, $\mu_{\mathrm{i}}$ is the exporting country's share of the economic distance bias, referred to by Anderson in [6], which is due to the influence of the behind the border constraints. This bias, which is country specific to the exporting country for each importer, creates the difference between actual and potential trade between the exporting and importing countries concerned. It is difficult to get full information on all behind the border constraints that exist within the exporting country. Nevertheless, drawing on Kalirajan and Singh in [15], the combined effect of these constraints can be modeled by the random variable $\mu_{\mathrm{i}}$ that takes values between 0 and 1 and is usually assumed to follow a truncated (at 0 ) distribution, $N\left(0, \sigma_{\mu}^{2}\right)$. When $\mu_{\mathrm{i}}$ is 0 , this indicates that the constraints are not important, and the actual exports and potential exports are the same (assuming there are no statistical errors). When $\mu_{\mathrm{i}}$ takes a value other than 0 (but less than or equal to 1 ), this indicates that the constraints are important, and they constrain actual exports from reaching potential exports. Thus, the term $\mu_{\mathrm{i}}$, which is bilateral observation-specific, represents the bias that is a function of the behind the border constraints within the exporting county's control. Unlike the conventional approach, this method of estimating the gravity model does not exclude the influence of economic distance bias on trade flows between two countries.

The error term $v_{i}$ captures the influence of omitted variables on trade flows and implicit beyond the border factors, in addition to measurement errors that are randomly distributed across observations in the sample. Implicit beyond the border constraints are not controlled by exporting countries, and it is assumed that these are randomly distributed, affecting the exporting countries uniformly. The random distribution of $v_{i}$ also implies efficient, conforming exporting countries could gain market share at the expense of less efficient countries in specific product markets in the importing country. The model formulation supports the assumption that $v_{i}$ is a double sided and is usually assumed to be $N\left(0, \sigma_{v}^{2}\right)$. 
With the stochastic framework followed in this analysis, in some cases when $v_{i}>0$ due to favorable external developments, it is possible that actual exports exceed estimated potential exports. For such situations, the results need to be interpreted as the realization of country's export potential. Moreover, measurement errors could also lead to these situations. Actual exports may also be different from potential exports due to measurement errors emanating from alternative trade institutions that have evolved over time due to the weakness of formal contracting institutions. Nunn and Trefler in [16] argue that these may deal with hold-up problems and could take the form of repeat relationships, ethnic networks, culture, and vertical integration. For example, repeated interactions could lead to the creation of non-kin-based networks that act as a substitute for legal contract enforcement and also help in sharing risk and pooling information. In this case, it would have an export-enhancing effect. Conversely, these alternative institutions are not without costs, as they may create barriers to entry and, when old partnerships become less productive, may result in inefficiencies. Gould in [17], while explaining trade with the USA, finds positive a correlation between the presence of immigrant populations from a particular country and trade with that particular country.

Nunn and Trefler in [16] further state that if there are underinvestment problems due to hold-up, and for example, if both parties underinvest, then this problem could be alleviated by allocating control to one party or the other. Therefore, vertical integration provides an additional tool to alleviate underinvestment. For example, in multinationals this decision could involve whether to incentivize the headquarters or supplier, with the final decision affecting the pattern of trade from a particular country.

To estimate a SFGM, maximum likelihood methods can be applied to either crosssectional or panel data to verify how important behind the border constraints are in limiting exports from their potential. In addition, estimating with this methodology also demonstrates whether total variations from the mean in the potential exports, given as $\sigma^{2}=$ $\sigma_{v}^{2}+\sigma_{\mu}^{2}$, are due to random factors $\sigma_{v}^{2}$ or country-specific behind the border constraints $\sigma_{\mu}^{2}$. The gamma coefficient $(\gamma)$ captures the total variation in the model due to the influence of country-specific institutional, socio-economic, and political factors that constitute the behind the border constraints to exports. This is given as $\gamma=\sigma_{\mu}^{2} / \sigma^{2}$. A large size and significance of gamma imply that country-specific behind the border constraints are responsible for a large proportion of the mean total variation in the model. 


\section{DATA}

The bilateral data for Iran's agricultural exports to 36 destination countries for the period of 1982-2017 were retrieved from the United Nations Commodity Trade Statistics (UN COMTRADE) database. The real GDP (2010 constant prices) and population data were obtained from the World Bank's World Development Indicators (WDI). The trade-weighted, effective applied tariff rates have been downloaded from the Trade Analysis and Information System (TRAINS) using World Integrated Trade Solutions (WITS World Bank). The bilateral population weighted distances are in kilometers and have been downloaded from GeoDIST. All the variables in the model are in natural logs except tariffs. Computer software FRONTIER 4.1 was used to estimate the SFGM (Coelli in [18]).

\section{RESULTS AND DISCUSSION}

Table (1) portrays estimation results for equation (2).

Table1. Estimation results of SFGM

\begin{tabular}{|c|c|c|c|c|}
\hline & Coefficient & Std Error & Z-Statistic & Prob \\
\hline Constant & 7.14 & 2.24 & 3.19 & 0.01 \\
\hline GDP & 0.54 & 0.12 & 4.50 & 0.008 \\
\hline Population & 0.02 & 0.01 & 2.00 & 0.03 \\
\hline Distance & -1.14 & 0.08 & -14.25 & 0.001 \\
\hline Tariff & -0.01 & 0.005 & -2.00 & 0.03 \\
\hline$\sigma_{v}$ & 0.25 & & & 0.001 \\
\hline$\sigma_{u}$ & 1.04 & & & 0.12 \\
\hline$\sigma^{2}$ & 1.25 & & & 0.002 \\
\hline$\gamma$ & 0.79 & & & 0.001 \\
\hline Log likelihood & -123.14 & & & \\
\hline Wald $\boldsymbol{c h} \boldsymbol{i}^{2}$ & 126.57 & & & \\
\hline Observations & $36 \times 36$ & & & \\
\hline
\end{tabular}


The coefficients of GDP and population of the trade partners, and distance from Iran, have the expected signs, though the impact of distance is much greater than GDP. The estimated $\sigma^{2}$ is significant implying that variation of export potentials in the period was considerable but this variation is due to random factors $\sigma_{v}^{2}$ only. The significance and level of $\gamma$ suggests that almost three-fourths of the estimated variations in Iran's potential agricultural exports with its trading partners were due to behind the border constraints. Moreover, tariffs imposed by trade partners are estimated to be another significant factor on Iran's agricultural exports. A similar result was found by Roosta et al. in [11] and Kalirajan in [12].

Based on the results provided in Table 1, potential agricultural exports has been calculated for each importer and is presented in Tables 2. The comparison between actual and potential values for each country provides an estimate of the export capacity utilization with the respective countries and the extent to which trade is limited by behind the border constraints. The highest rate of exports potential realization relates to Syria which has close political and economic ties with Iran. Some major European partners such as France, Italy, and the Netherlands show same result. Countries with great unrealized exports capacity are Saudi Arabia, Hong Kong, South Korea, China, and Sri Lanka. It means that Iranian government, especially Ministry of Agriculture, should pay special attention to expansion of markets in this group of countries. 
Table2. Iran's actual and potential agricultural exports by importer (average over 1982-2017)

\begin{tabular}{|c|c|c|c|}
\hline Importer & $\begin{array}{l}\text { Actual Exports (1000USD) } \\
\text { (1) }\end{array}$ & $\begin{array}{l}\text { Potential Exports (1000USD) } \\
\text { (2) }\end{array}$ & $(1) /(2)$ \\
\hline Germany & 897832.7 & 1282618.1 & 0.70 \\
\hline Italy & 454955.9 & 541614.1 & 0.84 \\
\hline Turkey & 342475.6 & 482360.0 & 0.71 \\
\hline Iraq & 280167.8 & 466946.3 & 0.60 \\
\hline United Arab Emirates & 229245.2 & 301638.4 & 0.76 \\
\hline Pakistan & 179078.2 & 284251.1 & 0.63 \\
\hline China & 163732.2 & 314869.6 & 0.52 \\
\hline India & 157652.5 & 222045.7 & 0.71 \\
\hline Azerbaijan & 122295.2 & 160914.7 & 0.76 \\
\hline Afghanistan & 89671.8 & 137956.6 & 0.65 \\
\hline Turkmenistan & 57461.9 & 79808.1 & 0.72 \\
\hline Poland & 50452.2 & 62286.6 & 0.81 \\
\hline Belgium & 39313.5 & 57813.9 & 0.68 \\
\hline Vietnam & 39309.3 & 71471.4 & 0.55 \\
\hline Switzerland & 36471.7 & 52857.5 & 0.69 \\
\hline Ukraine & 28606.6 & 40866.5 & 0.70 \\
\hline United Kingdom & 27533.8 & 33577.8 & 0.82 \\
\hline France & 22073.2 & 25968.4 & 0.85 \\
\hline Hong Kong & 22042.4 & 44984.4 & 0.49 \\
\hline Uzbekistan & 21084.3 & 39781.6 & 0.53 \\
\hline Russian Federation & 20532.6 & 29757.3 & 0.69 \\
\hline Bangladesh & 17490.8 & 22715.3 & 0.77 \\
\hline Spain & 17287.7 & 26193.4 & 0.66 \\
\hline Sri Lanka & 17196.2 & 32445.6 & 0.53 \\
\hline Netherlands & 14211.4 & 16334.9 & 0.87 \\
\hline Qatar & 10397.6 & 15068.9 & 0.69 \\
\hline Armenia & 10228.7 & 14011.9 & 0.73 \\
\hline Georgia & 9959.2 & 13458.3 & 0.74 \\
\hline Kuwait & 9256.5 & 11867.3 & 0.78 \\
\hline South Korea & 8684.2 & 17027.8 & 0.51 \\
\hline Saudi Arabia & 6999.9 & 16666.4 & 0.42 \\
\hline Philippines & 6839.1 & 11591.6 & 0.59 \\
\hline Egypt & 6464.7 & 11544.1 & 0.56 \\
\hline Japan & 6406.7 & 7718.9 & 0.83 \\
\hline Indonesia & 5779.6 & 6643.2 & 0.87 \\
\hline Syrian Arab Republic & 5379.2 & 6044.0 & 0.89 \\
\hline Average & 95404.7 & 137881.2 & 0.69 \\
\hline
\end{tabular}




\section{CONCLUSIONS}

Empirical estimation was performed to investigate the presence of institutional, socioeconomic and political behind the border impediments to Iran's agricultural exports during 1982-2017 using stochastic frontier gravity model. In the SFGM framework, which considers both the demand and supply side effects, the results showed significant direct impact of partners' GDP and population on Iran's agricultural exports. Opposite relationship was found for partners' import tariff and geographical distance between countries. The empirical results also demonstrate that Iran is not realizing its full agricultural exports potential with its main partners including neighboring countries. Iran needs more regional focus in order to smooth consumption across borders and insulate the region from future shocks. Besides, signing bilateral and regional agreements to set preferential tariff regime, can lead to more realization of exports capacity.

Conflicts of Interest: The author(s) declare that there are no conflicts of interest regarding the publication of this paper.

\section{References}

[1] A.K. Miankhel, A.K. Kaliappa, and S.M. Thangavelu, Australia's export potential: an exploratory analysis, J. Asia. Pac. Econ. 19 (2) (2014), 230-246.

[2] S.L. Baier, and J. H. Bergstrand, Bonus vetus OLS: A simple method for approximating international trade-cost effects using gravity equation, J. Int. Econ. 77 (2009), 77-85.

[3] J. E. Anderson, and E. van Wincoop, Gravity with gravitas: a solution to the border puzzle, Amer. Econ. Rev. 93 (1) (2003), 170-192.

[4] S. Linder, An essay in trade and transformation, New York: Wiley, (1961).

[5] J. Tinbergen, Shaping the world economy: suggestions for an international economic policy, New York: Twentieth Century Fund, (1962).

[6] J. E. Anderson, A theoretical foundation for the gravity equation, Amer. Econ. Rev. 69 (1) (1979), 106-116.

[7] J. H. Bergstrand, Jeffrey, The gravity equation in international trade: some microeconomic foundations and empirical evidence, Rev. Econ. Stat. 67 (3) (1985), 474-481.

[8] E. Helpman, and P.Krugman, Market structure and foreign trade: increasing returns, imperfect competition, and the international economy. Cambridge, MA: MIT Press, (1985). 
[9] A. V. Deardoff, Determinants of bilateral trade: does gravity work in the neoclassical world? NBER Working Papers 5377, National Bureau of Economic Research, Inc, (1995).

[10] Central Bank of Iran, Statistical yearbook, (2017).

[11] R. A. Roosta, R. Moghaddasi, and S. S. Hosseini, Export target markets of medicinal and aromatic plants, J. App. Res. Med. Arom. Plant. 7 (1) (2017), 84-88.

[12]K. Kalirajan, Regional cooperation and bilateral trade flows: an empirical measurement of resistance model, Intl. Trade. J. 21 (2) (2007), 195-209.

[13]J. M. C. S. Silva, and S. Tenreyro, Gravity-defying trade, Working Paper 03, Federal Reserve Bank of Boston, Boston, Mass (2003).

[14] L. Mátyás, L, Proper econometric specification of the gravity model, World. Econ. 20 (1997), 363368.

[15]K. Kalirajan, and K. Singh, A comparative analysis of recent export performances of China and India, Asian. Econ. Papers. (2007).

[16]N. Nunn, and D. Trefler, Domestic institutions as a source of comparative advantage, Working Paper 18851, National Bureau of Economic Research (NBER), Cambridge MA, (2013).

[17]D. M. Gould, Immigrants link to the home country: empirical implications for U.S. bilateral trade flows, Rev. Econ. Stat. 76 (2) (1994), 1-25.

[18] T. Coelli, A guide to frontier version 4.1: a computer program for stochastic frontier production and cost function estimation, Center for Efficiency and Productivity Analysis Working Paper 96/07, University of New England, Armidale, Australia, (1996). 